\title{
Efficacy of i-PRF in regenerative endodontics therapy for mature permanent teeth with pulp necrosis: study protocol for a multicentre randomised controlled trial
}

Yuee Liang ${ }^{\dagger}$, Rongyang $\mathrm{Ma}^{\dagger}$, Lijuan Chen, Xingzhu Dai, Shiya Zuo, Weiyi Jiang, Naiming Hu, Zilong Deng ${ }^{*}$ and Wanghong Zhao*

\begin{abstract}
Background: Dental pulp necrosis, a common health problem, is traditionally treated with root canal therapy; however, it fails in restoring the vitality of damaged pulp. Most studies regarding regenerative endodontic therapy (RET) are limited to the treatment of immature necrotic teeth. Given that injectable platelet-rich fibrin (i-PRF) has shown great potential in regenerative medicine as a novel platelet concentration, this study is designed to explore whether i-PRF can serve as a biological scaffold, extending the indications for RET and improving the clinical feasibility of RET in mature permanent teeth with pulp necrosis.

Methods: This is a randomised, double-blind, controlled, multicentre clinical trial designed to evaluate the clinical feasibility of RET for mature permanent teeth with pulp necrosis and to compare the efficacy of i-PRF and blood clots as scaffolds in RET. A total of 346 patients will be recruited from three centres and randomised at an allocation ratio of 1:1 to receive RET with either a blood clot or i-PRF. The changes in subjective symptoms, clinical examinations, and imaging examinations will be tracked longitudinally for a period of 24 months. The primary outcome is the success rate of RET after 24 months. The secondary outcome is the change in pulp vitality measured via thermal and electric pulp tests. In addition, the incidence of adverse events such as discolouration, reinfection, and root resorption will be recorded for a safety evaluation.

Discussion: This study will evaluate the clinical feasibility of RET in mature permanent teeth with pulp necrosis, providing information regarding the efficacy, benefits, and safety of RET with i-PRF. These results may contribute to changes in the treatment of pulp necrosis in mature permanent teeth and reveal the potential of i-PRF as a novel biological scaffold for RET.
\end{abstract}

Trial registration: ClinicalTrials.gov NCT04313010. Registered on 19 March 2020

Keywords: Dental pulp necrosis, Regenerative endodontics therapy, Pulp regeneration, Blood clot, Injectable platelet-rich fibrin, Mature permanent teeth

* Correspondence: zldeng@yeah.net; wanghong_zhao@sina.com

†Yuee Liang and Rongyang Ma contributed equally to this work.

Department of Stomatology, Nanfang Hospital, Southern Medical University,

No. 1838, Guangzhou Avenue North, Guangzhou 510515, China

C C The Author(s). 2021 Open Access This article is licensed under a Creative Commons Attribution 4.0 International License, which permits use, sharing, adaptation, distribution and reproduction in any medium or format, as long as you give appropriate credit to the original author(s) and the source, provide a link to the Creative Commons licence, and indicate if changes were made. The images or other third party material in this article are included in the article's Creative Commons licence, unless indicated otherwise in a credit line to the material. If material is not included in the article's Creative Commons licence and your intended use is not permitted by statutory regulation or exceeds the permitted use, you will need to obtain permission directly from the copyright holder. To view a copy of this licence, visit http://creativecommons.org/licenses/by/4.0/ The Creative Commons Public Domain Dedication waiver (http://creativecommons.org/publicdomain/zero/1.0/) applies to the data made available in this article, unless otherwise stated in a credit line to the data. 


\section{Background}

Dental pulp necrosis has become one of the most common health problems being the sequelae of caries, trauma, and inappropriate endodontic treatments $[1,2]$. Necrosis of the dental pulp not only affects long-term tooth survival and preservation, but also can serve as a source of bacteria leading to the infection of periapical tissue and even the maxillofacial space. In addition, there is a strong correlation between oral infections and systemic diseases such as cardiovascular diseases and diabetes mellitus [3].

To date, root canal therapy (RCT) is the most acceptable treatment for pulp necrosis, based on the replacement of inflamed or necrotic pulp tissue with artificial filling materials [4]. However, this conventional therapy does not restore the vitality of damaged pulp or reconstitute the neurovascular system [5, 6]. Therefore, regenerative endodontic therapy (RET) has attracted increasing attention with the development of tissue engineering. RET applies the concept of tissue engineering (stem cells, biomimetic scaffolds, and bioactive growth factors) to achieve revascularization, innervation, and restoration of odontoblastic layers $[5,7,8]$. Unlike root canal therapy, the disinfected canals are filled with vital tissue in RET rather than biocompatible, nonvital foreign materials [9]. While several studies have explored the potential of pulp regeneration for infected teeth, most studies are limited to the treatment of immature necrotic teeth [10]. For mature permanent teeth, vital pulp is also of great importance in enhancing the immune system in root canals, promoting dentin deposition under chronic stimuli, and preventing discolouration [6]. But most of the reports of pulp regeneration in mature teeth are case reports or case series $[6,9,11,12]$ as mature teeth have fewer stem/progenitor cells, have narrower apical pathways for cell migration, and are more difficult to disinfect $[4,6,13]$. Hence, it is of great urgency to develop an improved RET procedure to maximise the regeneration potential of mature teeth and extend the indications of RET.

Scaffolds play a key role in RET, as they provide a favourable microenvironment for stem cells to migrate, proliferate, and differentiate [14-17]. Blood clot revascularization (BCR) is the most common revascularization method, in which the blood clot can serve as a scaffold and is formed by an endodontic file introduced into the root canal beyond the apical foramen to provoke bleeding from the periapical tissue [13, 18-20]. The evokedbleeding technique stimulates surviving dental pulp stem cells near the root apex to migrate into the root canal space, such as periodontal ligament stem cells and bone marrow mesenchymal stem cells [6, 21, 22]. However, blood clots are a poor source of growth factors [19], and the precise technique required to control the speed and volume of bleeding has limited its applications in clinical practice [20]. Furthermore, several studies regarding mature necrotic teeth reported that BCR resulted in a negative response to pulp sensibility after 8-26 months [23]. Therefore, the development of a bioscaffold with high concentration of pro-regenerative factors is an important topic in the field of pulp regeneration.

Platelet products have been used in tissue regeneration and dentistry for over two decades and have shown great potential in providing an optimal scaffold for pulp regeneration [24-27]. Platelet-rich fibrin (PRF), the second-generation platelet concentrate, is a kind of purely natural autologous fibrin matrix with trapped platelets and leukocytes, guaranteeing the prolonged release of growth factors and cytokines [19, 28, 29]. However, the solid-state of PRF limits its applications [30]. There is controversy regarding the performance of PRF in RET compared to that of the conventional blood clots and the first-generation platelet concentrate, plateletrich plasma (PRP) $[17,20]$. As the low-speed centrifugation concept (LSCC) was developed, injectable plateletrich fibrin (i-PRF) was developed as a novel liquid blood derivative in 2014. This liquid blood derivative is enriched with high concentrations of platelets, leukocytes, and growth factors [31-33]. Recent studies have reported that i-PRF provides a three-dimensional fibrindynamic gel embedded with platelets, leukocytes, type-I collagen, osteocalcin, and growth factors [31] with the potential to modulate inflammatory processes [34], exert anti-bacterium and anti-biofilm activities [35, 36], and promote osteogenesis [37-39]. Compared to PRF, i-PRF results in better bone regeneration [39], treatment of gingival recession defects [40], and elimination of endodontic infection [36]. However, there is no high-quality evidence regarding whether $\mathrm{i}-\mathrm{PRF}$, as an improved platelet product, could serve as an optimised scaffold in RET. At the same time, the lack of a standard protocol for RET with i-PRF also limits the use of i-PRF in RET, as different protocols may result in different treatment outcomes $[5,41,42]$.

Therefore, the main aim of this randomised, doubleblind, controlled, multicentre clinical trial is further evaluating the efficacy of RET in treating mature necrotic teeth, and exploring the feasibility of i-PRF as a scaffold in RET.

\section{Methods}

\section{Study design and objectives}

This is a randomised, double-blind, parallel positive control, multicentre clinical trial (Fig. 1) that aims to compare the efficacy of i-PRF and blood clots (BCs) as scaffolds in RET for mature permanent teeth with pulp necrosis. The protocol will be reported according to the Standard Protocol Items: Recommendations for 


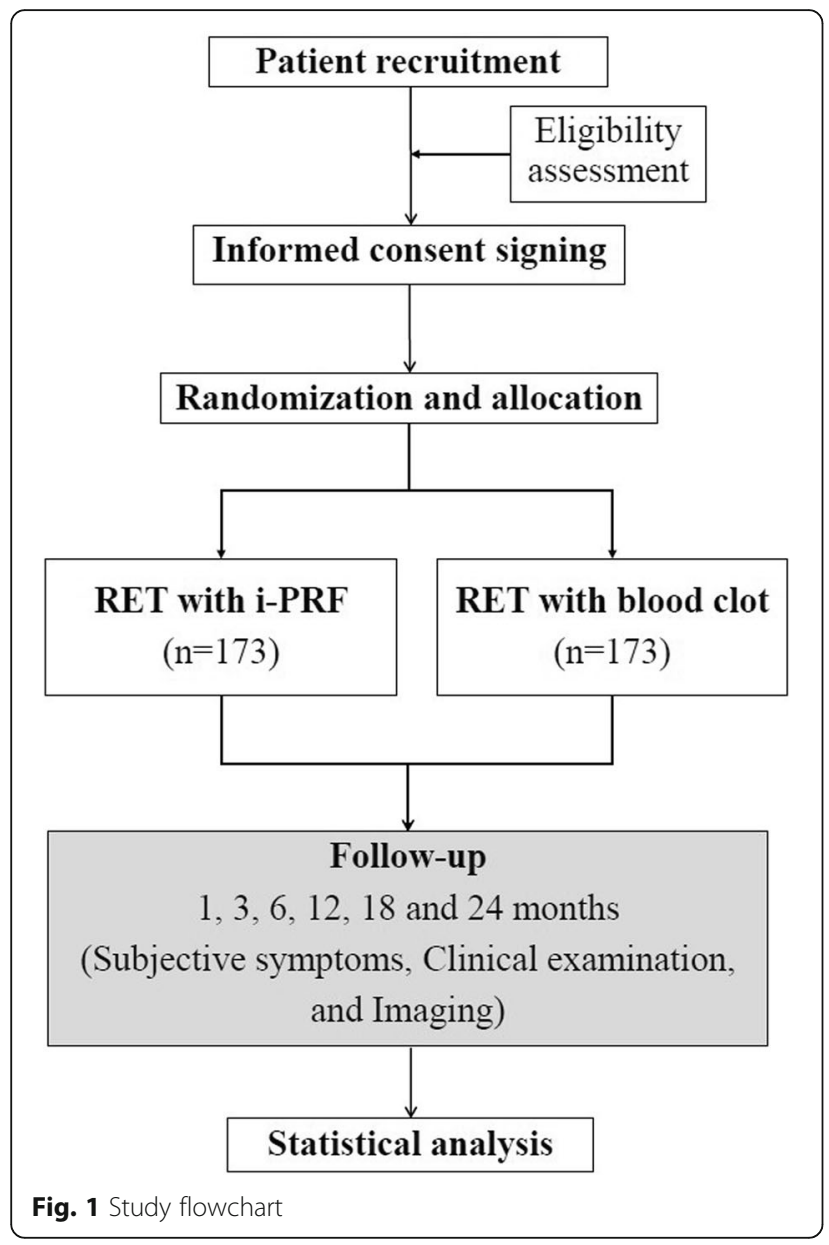

Interventional Trials (SPIRIT) statement (Additional file 1). After informed consent acquisition, all eligible patients $(n=346)$ will be randomly divided into two groups at an allocation ratio of 1:1. Patients in the test group will receive RET with $\mathrm{i}$-PRF while those in the control group will receive conventional RET with BC. The follow-up period will be 24 months, and clinical data will be collected at $1,3,6,12,18$, and 24 months after surgery. Figure 2 outlines the schedule of events for patients in the trial.

The primary objective of this study is to evaluate the efficacy of RET and RET with i-PRF for the treatment of mature permanent teeth with pulp necrosis. The secondary aim is to carefully investigate the factors influencing the clinical outcomes of RET in mature permanent teeth with pulp necrosis, and at the same time, to explore the standard RET protocol for treating mature permanent teeth with pulp necrosis.

\section{Study setting and recruitment}

The study will be carried out at three centres of Southern Medical University: NanFang Hospital, Stomatological Hospital, and Shenzhen Hospital. Two dentists from each centre will participate in this trial after receiving standardised training to obtain a comprehensive overview of the rationale and strategy of the standard intervention procedure. A total of 346 patients will be recruited via outpatient hospital clinics by researchers of the above centres. After an eligibility assessment and informed consent, the patients will be randomly assigned to the control group or the experimental group at a ratio of 1:1. Patients who agree to participate in this study will sign an informed consent form.

\section{Inclusion criteria}

(1) Agree to participate in this study and provide informed consent

(2) Age 10-59 years at the time of enrolment

(3) At least one mature permanent tooth diagnosed with pulp necrosis (no response to pulp vital test) with or without periapical lesions

(4) Radiologic confirmation (cone beam CT (CBCT)) of a single root necrotic tooth with a single root canal

\section{Exclusion criteria}

(1) Teeth with severe coronal defects that require post and core as final restorations

(2) Non-restorable teeth

(3) Teeth with root fractures or split roots

(4) Presence of other pathological root resorptions

(5) Presence of periodontitis

(6) Allergies to any medications or materials necessary to complete the procedures

(7) Presence of dental dysplasia or other oral genetic disorders

(8) Women who are pregnant or lactating, or women who plan to become pregnant in the subsequent 2 years

(9) Presence of dental phobia

(10)Presence of mental disorders

(11)A history of systemic diseases that may alter immune function

(12)Medical conditions and/or receiving medications that affect healing or blood coagulation

(13)Participation in other clinical studies within the past 3 months

(14)Patients who are deemed unsuitable to participate in the study by investigators

\section{Dropout criteria}

(1) Presence of serious adverse events that doctors believe should lead to termination of trial participation, such as severe internal or external root resorption and tooth fracture 


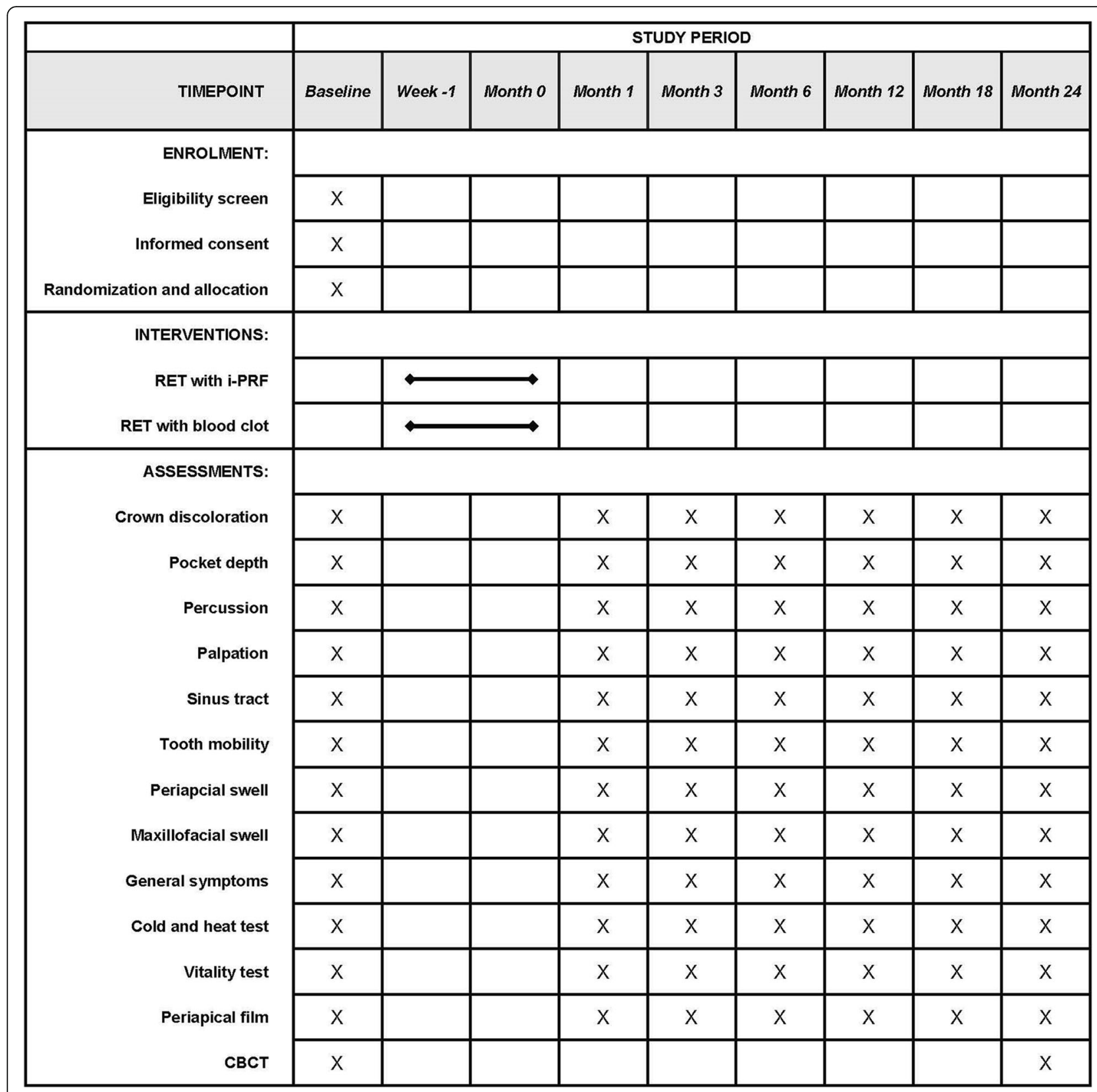

Fig. 2 Schedule of intervention and assessments. All study-related procedures are outlined in this figure. RET, regenerative endodontic therapy; $\mathrm{CBCT}$, cone beam computed tomography

(2) Poor clinical compliance

(3) Withdrawal of consent for study participation by the patient

\section{Randomisation, allocation, and blinding}

Eligible patients will be randomly assigned to one of two groups at an allocation ratio of $1: 1$. The randomisation sequence and grouping will be generated and stored by one researcher who will not be involved directly in participant screening, enrolment, or assessment, using SPSS 20.0 software (IBM Co., Armonk, NY, USA). All random numbers will be listed sequentially, and a set of 10 numbers will be arranged as a cluster (the first 5 for the test group and the last 5 for the control group). Then, random numbers and grouping are inserted in opaque and sealed envelopes sequentially. After all the envelopes have been sealed, they will be distributed to each research centre. Only dentists can open the envelope to check the group allocation and perform the interventions according to the instructions of this study. As a double-blind trial, the patients and outcome evaluators will be blinded to the group assignment until the 
completion of the study. As dentists cannot be blinded to treatment allocation due to the notable differences in the treatment methods, they will not be allowed to discuss the type of intervention with either patients or outcome evaluators.

\section{Interventions}

According to the latest RET operating guidelines issued by the American Academy of Endodontics (AAE) [43] and the European Society of Endodontics (ESE) [44], the standardised operating procedure of RET requires two treatment visits. During the first appointment, infection is controlled and inflammation is relieved. Pulp regeneration and revascularization is accomplished during the second appointment. All RET procedures will be performed under a dental microscope, except anaesthesia and rubber dam placement steps.

\section{First Appointment}

With the aim of infection control and inflammation relief, the first appointment will be the same for all patients in this study. The first appointment will include the following components:

(1) Anaesthesia and isolation. After local anaesthesia with articaine hydrochloride and epinephrine tartrate injection (with 1:100,000 adrenaline [Produits Dentaires Pierre Rolland, Merignac, France]), the tooth is isolated with a rubber dam and disinfected.

(2) Access preparation. All decayed areas of the tooth will be removed, and the pulp chamber will be completely unroofed.

(3) Root canal preparation. The working length and the initial apical file will be determined.

(4) Root canal irrigation. As canal disinfection relies considerably on chemical irrigants, the needle will be placed with the side-port vents into the apical third of the tooth and irrigation will be accomplished using needles with a slow infusion rate. The canal will be copiously irrigated in three steps using ultrasonic irrigation with interspersed drying with sterile paper points. A 5-min irrigation with $20 \mathrm{~mL}$ $1.0 \%$ sodium hypochlorite $(\mathrm{NaClO})$ (Longly biomedical, Wuhan, China) will be followed by a simple irrigation with $5-\mathrm{mL}$ sterile saline solution (Baxter Healthcare, Shanghai, China), ending with a 5-min irrigation with $20 \mathrm{~mL} 17 \%$ ethylene diamine tetraacetie acid (EDTA) (Longly biomedical, Wuhan, China).

(5) Medicated intra-pulpal dressings. To restrict bacterial regrowth and supply continued disinfection, the root canal will be filled homogeneously to the working length with calcium hydroxide paste (CALXYL X-Ray Visible, OCO Praparate GmBh, Dirmstein/Pfalz, Germany) [45]. Then, glass ionomer (GC Fuji IX, GC Corporation, Tokyo, Japan) will be placed onto the intracanal dressing.

\section{Second Appointment}

After 2-4 weeks, patients will return for a second visit. If the symptoms are not relieved, the root canals will be re-treated with calcium hydroxide. Patients with no symptoms will proceed to the next RET treatment steps (Fig. 3).

(1) Cleaning, anaesthesia, field isolation, disinfection of the operating field, and temporary seal removal

(2) Root canal irrigation. The canal will be irrigated with $20 \mathrm{~mL}$ of 17\% EDTA for 5 min to flush out the calcium hydroxide paste, followed by irrigation with sterile saline solution to decrease the cytotoxicity of EDTA. After drying the canal using sterile paper points, the two groups of patients will experience different revascularization procedures.

(3) PRF preparation. To prepare PRF, $10 \mathrm{~mL}$ of whole blood from the median cubital vein will be drawn into 10-ml plastic tubes (Kangjian Medical, Jiangsu, China) without anticoagulant reagent and centrifuged at $800 \mathrm{rpm}$ for $3 \mathrm{~min}$ with Centrifuge (Process for PRF, FRANC). After centrifugation, the upper yellow fluid liquid (i-PRF) will be collected as close as possible to the layer of red cells (Fig. 4).

(4) RET with i-PRF (the test group). K-files will be intentionally used to violate the periapical tissues via overinstrumentation up to $2-3 \mathrm{~mm}$ beyond the apical foramen to provoke bleeding. However, only the apex third of the root canal will be filled with blood. The i-PRF will be injected into the root canal to a level $3 \mathrm{~mm}$ below the cementoenamel junction (CEJ). After a 10-15-min period for coagulation, the PRF will be covered by a 3-mm layer of iRoot BP Plus (Innovative Bioceramix Inc., Vancouver, Canada).

(5) RET with $B C$ (the control group). K-files will be intentionally used to violate the periapical tissues via overinstrumentation up to $2-3 \mathrm{~mm}$ beyond the apical foramen to provoke bleeding. The blood will be permitted to fill the canal space to a level $3 \mathrm{~mm}$ below the CEJ. After a 10-15-min period for coagulation, the $\mathrm{BC}$ will be covered by a $3-\mathrm{mm}$ layer of iRoot BP Plus.

(6) Cavity restoration. A layer of self-adhering flowable composite (Kerr Dyad Flow, Kerr, CA, USA) will be applied on top of the iRoot BP Plus layer as a cavity liner, and the final filling will be accomplished with resin with adhesive for permanent restoration. 


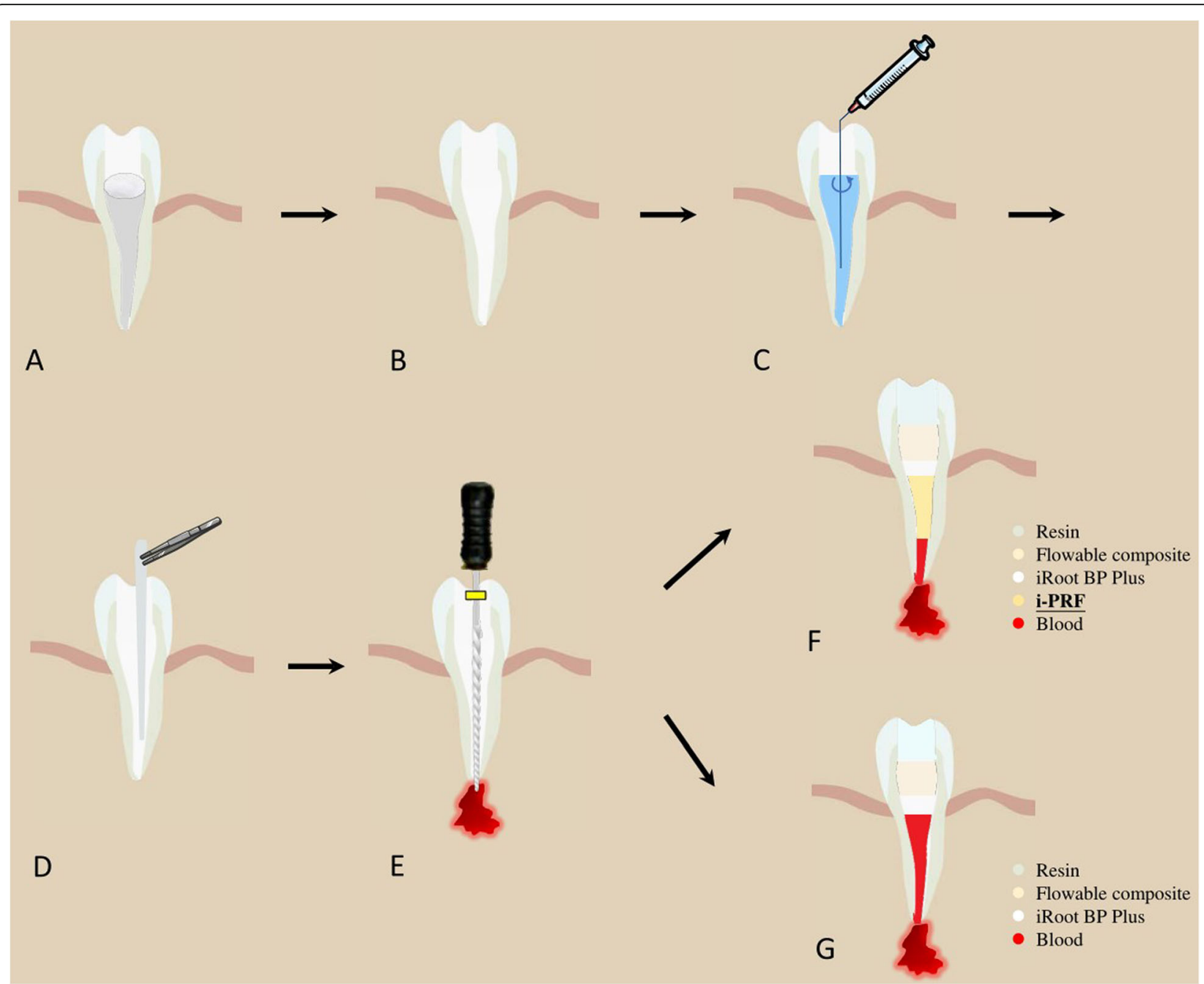

Fig. 3 Regenerative endodontics therapy procedures. The steps of regenerative endodontics therapy (RET) with injectable platelet-rich fibrin (iPRF) and with blood clot are shown. A After 2-4 weeks of intercanal medication, B the temporary seal is removed. C The root canal is irrigated and $\mathbf{D}$ dried with sterile paper points. E Bleeding is provoked. $\mathbf{F}$ i-PRF and cavity restoration are performed in the test group. G Blood clot and cavity restoration are performed in the control group

\section{Outcome measures}

Variables will be measured at baseline and at 1, 3, 6, 12, 18 , and 24 months after the treatment. At each appointment, a clinical examination, a periapical radiograph, and pulp tests (thermal and electric) will be performed. CBCT images will be obtained at baseline and 24 months after the treatment to evaluate the apical shadow. The primary outcome of this study is the success rate of RET 24 months postoperatively, which will be obtained by evaluating the clinical and radiographic outcomes. The secondary outcomes include the subjective response from the patient to thermal and electric stimuli, which reflects the responsiveness of regenerative pulpal sensory neurons. Safety will be evaluated via the analysis of the presence of adverse events during the study. The evaluators will complete standardised training prior to the study period. Two trained dentists will independently evaluate and disagreements will be resolved through a discussion with a third evaluator.

\section{Primary outcome measures}

The therapeutic effect evaluation criteria are the following:

(1) Success. After RET, the tooth is asymptomatic, with an absence of percussion pain, bone adhesion percussion sound, loosening, tenderness, mucosal swelling, sinus, or fistula. The radiographic examination demonstrates the absence of an apical shadow or a reduced apical shadow.

(2) Failure. After RET, the tooth is symptomatic, with symptoms of apical infection such as pain and 


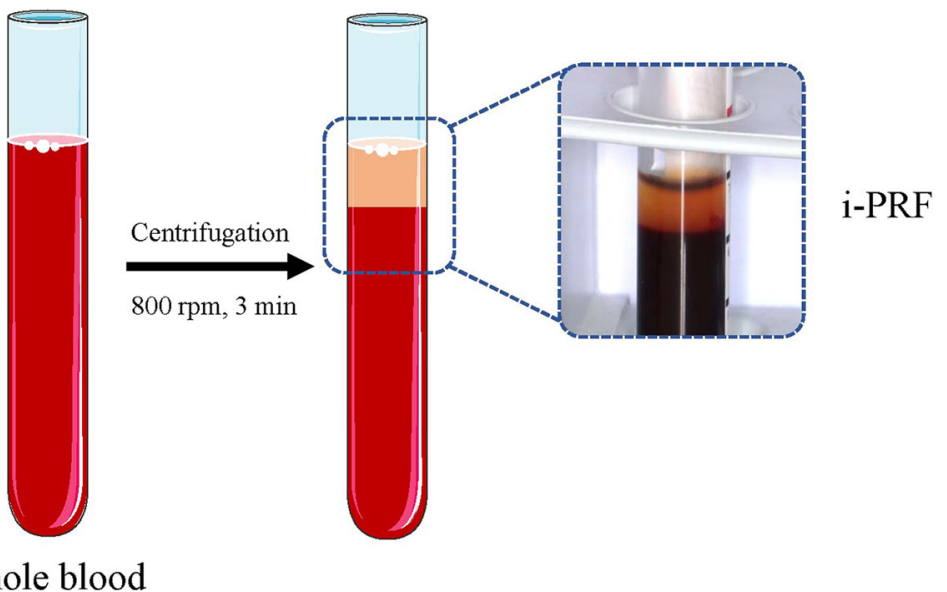

Fig. 4 The preparation of injectable platelet-rich fibrin. After centrifugation (800 rpm, 3 min), injectable platelet-rich fibrin (i-PRF) is collected from the upper yellow fluid liquid

fistula. The radiographic examination demonstrates a new-onset apical shadow or an enlarged apical shadow.

\section{Secondary outcome measures}

The preoperative results of the thermal pulp test and the electric pulp test will be recorded to ensure pulp necrosis of the involved tooth. The test results during the follow-up will be used to determine if the teeth included in the study regain sensitivity.

1. The results of thermal pulp test are as follows:

(a) Normal. The test tooth is considered normal if the patient responds similarly to when a control tooth is tested.

(b) Sensitive. The test tooth is considered sensitive if the patient experiences more pain than when a control tooth is tested.

(c) Dull. The test tooth is considered dull if the patient has a much slower, reduced response when stimulated compared to when a control tooth is tested at the same temperature.

(d) No response. The tested tooth is considered to have no response if the patient does not respond to stimulation.

2. The results of electric pulp test are as follows:

(a) The numerical reading is recorded when the patient elicits a response. To ensure consistency, each tooth will be tested twice and the average result will be used in the analyses.

\section{Safety evaluation}

All information regarding adverse events during the study will be recorded in detail, including symptoms, signs, onset time, and severity. Some possible adverse events that may be attributed to RET include reinfection of the root canal, external root resorption, internal root resorption, and discolouration.

\section{Sample size and statistical methods Sample size}

The primary outcome measure is the success rate at 24 months after treatment. According to nQuery Advenced 8.6 software (Statistical Solutions Ltd., Cork, Ireland), a sample size of 346 (173 for each group) patients is required when $\alpha=0.05$ and the test power is $80 \%$.

\section{Data collection methods and data management}

Data associated with this study will be collected in the standardised case report form (CRF) for the outcome analysis, and a specific supervisor will be responsible for reviewing the integrity, accuracy, and consistency of the data. To ensure the accuracy of data entry, two researchers will be responsible for entering the data independently and data query forms (DQF) will be resolved by tracing the source data. All the data will be registered in document clouds, and only authorised researchers will have access. Data monitoring committee consists of the Department of Biomedical Statistics, Southern Medical University, independent from the sponsor and competing interests.

As for the audition of this study, the frequency is once a year. During the audition, the project organisation will review the test process and make a comprehensive evaluation. The process will be independent of investigators and the sponsor.

\section{Statistical analysis}

The data will be analysed by an independent statistician using SPSS 20.0 software (IBM Co., Armonk, NY, USA) at the end of the study to evaluate the evolution. The continuous variables will be described as the mean 
(standard deviation) or median and analysed using parametric methods. Categorical variables will be described as percentages and analysed using non-parametric methods. The level of significance will be $P<0.05$, and 95\% confidence intervals will be calculated.

\section{(1) Baseline analysis}

The two groups will be comparable in terms of sex, age, tooth position, disease type, and apical hole size. Quantitative variables will be analysed using a one-way analysis of variance (independent sample t-test) or nonparametric methods if the data do not meet and cannot be transformed to meet parametric assumptions. Qualitative variables will be analysed using the Wilcoxon rank-sum test. A principal component analysis will be performed using multinomial logistic regression to adjust for potential confounders.

\section{(2) Main outcome analysis}

The inter-group comparison of success rates will be analysed using the chi-square test. If there are baseline variables influencing the comparability of the two groups, a logistic regression model will be used to eliminate the effects of these confounders on the success rate and the odds ratio (OR) will be calculated. For the missing data, the last observation carry forward method will be adopted to fill the validity analysis, that is, the case data that fails to observe the whole treatment process will be transferred to the final result of the test with the last observation data.

\section{(3) Secondary outcome analysis}

For intra-group comparisons, McNemar's test will be used to analyse the clinical outcomes of different centres. For inter-group comparisons, the secondary outcome will be analysed using the Chi-square test.

\section{(4) Safety evaluation analysis}

The adverse events that occur during the study period will be listed for each group and compared using the chi-square test. The security evaluation does not evaluate missing data.

\section{Ethics and dissemination}

The protocol has been approved by the Medical Ethics Committee of NanFang Hospital of Southern Medical University (reference NFEC-2019-233) and registered at ClinicalTrials.gov (reference NCT04313010). Any amendments to the protocol will be reviewed and approved by the ethics committee and funding support departments. Written informed consent will be obtained from all patients. The results will be published in the peer-reviewed journal and presented at conference presentations.

The Data Management Coordinating Centre will oversee the intra-study data sharing process, with the involvement of the Data Management Subcommittee. Only the principal investigator will be given access to all the data with a special password. Other project investigators will have direct access to their own site's data sets, and other sites' data by request. To ensure confidentiality, data dispersed to project team members will be blinded to any identifying participant information.

As for ancillary and post-trial care, all the patients who participated in the study could receive compensation from the study unit, including additional medical care, compensation or damages.

\section{Discussion}

As decades of evidence demonstrates the benefits of RET in immature teeth, the technique has recently been extended to mature teeth as an alternative to conventional endodontic treatments $[23,46]$. As RET in mature teeth is challenging, there is a lack of long-term clinical trials evaluating the feasibility of RET in mature necrotic teeth. In our study, the feasibility of RET for mature teeth can be tracked longitudinally by comprehensively considering subjective symptoms, clinical examinations, and imaging studies. The feasibility of using i-PRF, a novel and advanced PRF, as a biological scaffold for pulp regeneration will also be investigated. Therefore, this study will explore the feasibility of RET and of RET with i-PRF in mature necrotic teeth and develop a scientific treatment protocol to maximise the potential of $\mathrm{i}$-PRF in RET.

Platelet products have shown great potential in regenerative medicine due to their potency in storing and releasing biologically active substances, regulating the innate immune response, and combatting infection [2427]. Therefore, several studies regarding the potential of platelet products for pulp regeneration have been conducted. Platelet-rich plasma (PRP), 95\% of which is platelets, is the first-generation platelet concentrate [47]. PRP can promote endothelial progenitor cells to form vessel-like structures [48] and the regeneration of pulplike tissue $[48,49]$ in immature teeth. However, the protocol for harvesting PRP involves the use of anticoagulants and multiple centrifugation steps with high gforces $[27,28]$, and growth factors are released from PRP in a burst-like kinetic manner [50,51]. As a result, $\mathrm{PRF}$, the second-generation platelet concentrate derived from patient venous blood through single-step centrifugation, has emerged as a purely natural autologous fibrin matrix with trapped platelets and leukocytes, 
guaranteeing the prolonged release of growth factors and cytokines [19, 28, 29]. Since then, there are increasing researches devoted to optimising the protocol to obtain better platelet concentrates to meet different clinical needs. Leukocyte- and platelet-rich-fibrin (L-PRF), the first blood-derived PRF matrix without anticoagulants, has the potential to improve tissue healing in clinical cases $[26,31,52-54]$. Then, based on lower centrifugation speeds, advanced PRFs (A-PRF and A-PRF+) have been developed with a porous structure and more neutrophilic granulocytes $[28,29,45]$. Thus, the LSCC has been developed [55-57] to obtain PRF with a higher pro-regenerative potency. In 2014, i-PRF was developed. As a flexible matrix, i-PRF overcomes the limitations of the solid PRF matrix [31-33]. Thus, i-PRF has potential as an optimal scaffolding material in RET in mature teeth. Randomised controlled clinical trials are needed to provide high-quality evidence to evaluate the feasibility of RET with i-PRF and, at the same time, explore the standard clinical protocol.

One of the challenges of performing RET in mature permanent teeth is that there is no agreement in the size of the apical foramen for new tissue to grow into the canals. Earlier, it was been found that foramens smaller than $1 \mathrm{~mm}$ (measured on radiographs) would prevent the revascularization of the pulp tissue [58]. As a result, many endodontists preferred to mechanically prepare the root canal to a large apical size when performing RET on mature teeth. An animal model study reported that an apical foramen $0.32 \mathrm{~mm}$ in diameter did not prevent revascularization and ingrowth of new tissue into canals after transplantation [59]. A range of apical foramen diameters have been attempted in the previous reports of RET on mature teeth, including $1.0 \mathrm{~mm}$ [11], $0.6 \mathrm{~mm}$ [6], and $0.4 \mathrm{~mm}$ [9]. With the deepening of research, it has been revealed that enlargement of the apical foramen to at least $1 \mathrm{~mm}$ in diameter is unnecessary for RET [9]. Thus, in this study, we plan to use the conventional canal preparation protocol and avoid excessive preparation, which can increase the risk of root fracture.

The clinical efficacy of RET for mature necrotic teeth depends heavily on disinfection regimens. In this study, $20 \mathrm{~mL}$ of $1.0 \% \mathrm{NaClO}$ will be used for irrigation with a side-vented needle and an ultrasonic irrigation device to minimise the possibility of extrusion of irrigates into the periapical space and to enhance the disinfection efficacy of $\mathrm{NaClO}$. Following the recommendation from the $\mathrm{AAE}, \mathrm{NaClO}$ should be flushed away from the root canal with saline to reduce any lingering toxicity $[4,60]$. EDTA irrigation will also be applied in this study, as EDTA has been demonstrated to promote the survival of stem cells [61], stimulate the release of growth factors embedded in the dentin matrix, and enhance the odontogenic differentiation of migrated cells and angiogenesis
[6]. As for the intercanal medication of RET, the AAE and ESE have issued differing recommendations regarding intercanal medication during RET. The AAE recommends triple antibiotic paste (TAP), consisting of metronidazole, ciprofloxacin, and minocycline, while the ESE recommends the use of non-staining calcium hydroxide due to the risk of crown discolouration caused by TAP $[45,62]$. TAP cannot be fully removed from root canal systems via current irrigation techniques, potentially due to its penetration and binding to dentin [63]. Thus, to restrict bacterial regrowth and supply continued disinfection, the root canals will be filled homogeneously to the working length with calcium hydroxide in this study. In addition, unlike most existing studies, iRoot BP Plus will be used as the pulp capping material instead of mineral trioxide aggregrate (MTA), due to its satisfactory biocompatibility, sealing ability, antibacterial activity, and ability to upregulate the expression of mineralization-related genes [64].

Finally, to the best of our knowledge, this is the first multicentre clinical trial to evaluate the clinical efficacy of RET in mature necrotic teeth and to evaluate i-PRF as a novel biological scaffold for pulp regeneration. Although there is a concern that this study does not include histological or morphological analyses to determine the nature of the tissues formed in response to the treatment, this study will provide high-quality evidence guiding the future of RET practice on mature permanent teeth via the comprehensive evaluation of symptoms, clinical evaluations, and radiographic assessments. Therefore, our study will contribute to explore the maximum potential of RET and RET with i-PRF in mature necrotic teeth.

\section{Trial status}

This trial is in the process of recruiting participants.

\section{Abbreviations}

RET: Regenerative endodontic therapy; i-PRF: Injectable platelet-rich fibrin; RCT: Root canal therapy; BCR: Blood clot revascularization; PRF: Platelet-rich fibrin; PRP: Platelet-rich plasma; LSCC: Low-speed centrifugation concept; BCs: Blood clots; AAE: American Academy of Endodontics; ESE: European Society of Endodontics; CEJ: Cementoenamel junction; CBCT: Cone beam computed tomography; NaClO: Sodium hypochlorite; EDTA: Ethylene diamine tetraacetie acid; CRF: Case report form; DQF: Data query forms; OR: Odds ratio; TAP: Triple antibiotic paste; MTA: Mineral trioxide aggregrate

\section{Supplementary Information}

The online version contains supplementary material available at https://doi. org/10.1186/s13063-021-05401-7.

Additional file 1. SPIRIT 2013 Checklist: Recommended items to address in a clinical trial protocol and related documents.

\section{Acknowledgements}

The authors would like to thank the clinical research teams at each of the clinical sites involved in the study. 


\section{Authors' contributions}

YEL participated in the design of the study, and recruited participants. RYM drafted the manuscript. $L C$ recruited participants and performed the statistical analysis. XZD and SYZ collected case data. WYJ and RYM participated in the design of outcome measures and performed the evaluation of the clinical and radiographic outcomes. $\mathrm{NMH}$ assisted with participant recruitment and screening. WHZ and ZLD conceived the study, participated in its design and coordination, and helped draft the manuscript. The authors read and approved the final manuscript.

\section{Funding}

The work is funded by the Clinical Research Program of Southern Medical University (No. LC2019ZD023); the Clinical Research Program of Nanfang Hospital, Southern Medical University (No. 2020CR029); and the President Foundation of Nanfang Hospital, Southern Medical University (No. 2019Z019). The study funder plays no role in study design; collection, management, analysis, or interpretation of the data; or writing/submitting the manuscript.

\section{Availability of data and materials}

The datasets analysed during the current study are available from the corresponding author on reasonable request.

\section{Declarations}

\section{Ethics approval and consent to participate}

The protocol has been approved by the Medical Ethics Committee of NanFang Hospital of Southern Medical University (NFEC-2019-233). The study protocol has been registered on ClinicalTrials.gov (NCT04313010). The purpose, procedures, and potential risks of the trial will be clearly explained to the participants. Written informed consent will be obtained from all patients.

\section{Consent for publication}

Not applicable

\section{Competing interests}

All authors have no conflicts of interest to declare.

\section{Received: 4 May 2021 Accepted: 25 June 2021}

Published online: 06 July 2021

\section{References}

1. Peres MA, Macpherson LMD, Weyant RJ, Daly B, Venturelli R, Mathur MR, et al. Oral diseases: a global public health challenge. Lancet. 2019; 394(10194):249-60. https://doi.org/10.1016/S0140-6736(19)31146-8.

2. Righolt AJ, Jevdjevic M, Marcenes W, Listl S. Global-, regional-, and countrylevel economic impacts of dental diseases in 2015. J Dent Res. 2018;97(5): 501-7. https://doi.org/10.1177/0022034517750572.

3. Sasaki H, Hirai K, Martins C, Furusho H, Battaglino R, Hashimoto K. Interrelationship between periapical lesion and systemic metabolic disorders. Curr Pharm Des. 2016;22(15):2204-15. https://doi.org/10.2174/13 81612822666160216145107.

4. Schmalz G, Widbiller M, Galler KM. Clinical perspectives of pulp regeneration. J Endod. 2020;46(9S):S161-S74. https://doi.org/10.1016/j.joen.2 020.06.037.

5. Kim SG, Malek M, Sigurdsson A, Lin LM, Kahler B. Regenerative endodontics: a comprehensive review. Int Endod J. 2018;51(12):1367-88. https://doi.org/1 0.1111/iej.12954.

6. Paryani K, Kim SG. Regenerative endodontic treatment of permanent teeth after completion of root development: a report of 2 cases. J Endod. 2013; 39(7):929-34. https://doi.org/10.1016/j.joen.2013.04.029.

7. Mao J, Kim S, Zhou J, et al. Regenerative endodontics: barriers and strategies for clinical translation. Dent Clin N Am. 2012;56(3):639-49. https:// doi.org/10.1016/j.cden.2012.05.005.

8. Adnan S, Ullah R. Top-cited articles in regenerative endodontics: a bibliometric analysis. J Endod. 2018;44(11):1650-64. https://doi.org/10.1016/j. joen.2018.07.015.

9. Saoud TM, Martin G, Chen $\mathrm{YH}$, et al. Treatment of mature permanent teeth with necrotic pulps and apical periodontitis using regenerative endodontic procedures: a case series. J Endod. 2016;42(1):57-65. https://doi.org/10.1016/ j.joen.2015.09.015.
10. Nosrat A, Seifi A, Asgary S. Regenerative endodontic treatment (revascularization) for necrotic immature permanent molars: a review and report of two cases with a new biomaterial. J Endod. 2011;37(4):562-7. https://doi.org/10.1016/j.joen.2011.01.011.

11. Saoud TM, Sigurdsson A, Rosenberg PA, Lin LM, Ricucci D. Treatment of a large cystlike inflammatory periapical lesion associated with mature necrotic teeth using regenerative endodontic therapy. J Endod. 2014;40(12):2081-6.

12. Wang $Y$, Zhu $X$, Zhang C. Pulp revascularization on permanent teeth with open apices in a middle-aged patient. J Endod. 2015;41(9):1571-5. https:// doi.org/10.1016/j.joen.2015.04.022.

13. Gomes-Filho JE, Duarte PC, Ervolino E, et al. Histologic characterization of engineered tissues in the canal space of closed-apex teeth with apical periodontitis. J Endod. 2013;39(12):1549-56. https://doi.org/10.1016/j.joen.2 013.08.023.

14. Lovelace TW, Henry MA, Hargreaves KM, Diogenes A. Evaluation of the delivery of mesenchymal stem cells into the root canal space of necrotic immature teeth after clinical regenerative endodontic procedure. J Endod. 2011;37(2):133-8. https://doi.org/10.1016/j.joen.2010.10.009.

15. Torabinejad M, Turman M. Revitalization of tooth with necrotic pulp and open apex by using platelet-rich plasma: a case report. J Endod. 2011;37(2): 265-8. https://doi.org/10.1016/j.joen.2010.11.004.

16. Eramo S, Natali A, Pinna R, Milia E. Dental pulp regeneration via cell homing Int Endod J. 2018;51(4):405-19. https://doi.org/10.1111/iej.12868.

17. Lv H, Chen Y, Cai Z, Lei L, Zhang M, Zhou R, et al. The efficacy of plateletrich fibrin as a scaffold in regenerative endodontic treatment: a retrospective controlled cohort study. BMC Oral Health. 2018;18(1):139. https://doi.org/10.1186/s12903-018-0598-z.

18. Murray PE. Platelet-rich plasma and platelet-rich fibrin can induce apical closure more frequently than blood-clot revascularization for the regeneration of immature permanent teeth: a meta-analysis of clinical efficacy. Front Bioeng Biotechnol. 2018;6:139. https://doi.org/10.3389/fbioe.2 018.00139.

19. Shivashankar W. Comparison of the Effect of PRP, PRF and induced bleeding in the revascularization of teeth with necrotic pulp and open apex: a triple blind randomized clinical trial. J Clin Diagn Res. 2017;11(6): ZC34-9. https://doi.org/10.7860/JCDR/2017/22352.10056.

20. Narang I, Mittal N, Mishra N. A comparative evaluation of the blood clot, platelet-rich plasma, and platelet-rich fibrin in regeneration of necrotic immature permanent teeth: a clinical study. Contemp Clin Dent. 2015;6(1): 63-8. https://doi.org/10.4103/0976-237X.149294.

21. Seo B, Miura M, Gronthos S, et al. Investigation of multipotent postnatal stem cells from human periodontal ligament. Lancet (London, England). 2004;364(9429):149-55

22. Chrepa V, Henry MA, Daniel BJ, Diogenes A. Delivery of apical mesenchymal stem cells into root canals of mature teeth. J Dent Res. 2015;94(12):1653-9. https://doi.org/10.1177/0022034515596527.

23. Nageh M, Ahmed GM, El-Baz AA. Assessment of regaining pulp sensibility in mature necrotic teeth using a modified revascularization technique with platelet-rich fibrin: a clinical study. J Endod. 2018;44(10):1526-33.

24. Nurden AT. Platelets, inflammation and tissue regeneration. Thromb Haemost. 2011;105(Suppl 1):S13-33.

25. Barbeck M, Najman S, Stojanovic S, et al. Addition of blood to a phycogenic bone substitute leads to increased in vivo vascularization. Biomed Mater. 2015;10(5):055007. https://doi.org/10.1088/1748-6041/10/5/055007.

26. Cabaro S, D'Esposito V, Gasparro R, Borriello F, Granata F, Mosca G, et al. White cell and platelet content affects the release of bioactive factors in different blood-derived scaffolds. Platelets. 2018;29(5):463-7. https://doi. org/10.1080/09537104.2017.1319046.

27. Fujioka-Kobayashi M, Katagiri H, Kono M, Schaller B, Zhang Y, Sculean A, et al. Improved growth factor delivery and cellular activity using concentrated platelet-rich fibrin (C-PRF) when compared with traditional injectable (i-PRF) protocols. Clin Oral Investig. 2020;24(12):4373-83. https:// doi.org/10.1007/s00784-020-03303-7.

28. El Bagdadi K, Kubesch A, Yu X, et al. Reduction of relative centrifugal forces increases growth factor release within solid platelet-rich-fibrin (PRF)-based matrices: a proof of concept of LSCC (low speed centrifugation concept). Eur J Trauma Emerg Surg. 2019;45(3):467-79. https://doi.org/10.1007/s00068017-0785-7.

29. Lei L, Yu Y, Han J, Shi D, Sun W, Zhang D, et al. Quantification of growth factors in advanced platelet-rich fibrin and concentrated growth factors and their clinical efficacy as adjunctive to the GTR procedure in periodontal 
intrabony defects. J Periodontol. 2020;91(4):462-72. https://doi.org/10.1002/ JPER.19-0290.

30. Aydinyurt HS, Sancak T, Taskin C, Basbugan Y, Akinci L. Effects of Injectable platelet-rich fibrin in experimental periodontitis in rats. Odontology. 2021; 109(2):422-32. https://doi.org/10.1007/s10266-020-00557-1 Epub 2020 Oct 17. PMID: 33068206.

31. Varela HA, Souza JCM, Nascimento RM, Araújo RF Jr, Vasconcelos RC, Cavalcante RS, et al. Injectable platelet rich fibrin: cell content, morphological, and protein characterization. Clin Oral Investig. 2019;23(3): 1309-18. https://doi.org/10.1007/s00784-018-2555-2.

32. Gasparro R, Adamo D, Masucci M, Sammartino G, Mignogna MD. Use of injectable platelet-rich fibrin in the treatment of plasma cell mucositis of the oral cavity refractory to corticosteroid therapy: a case report. Dermatol Ther. 2019;32(5):e13062. https://doi.org/10.1111/dth.13062 Epub 2019 Aug 23. PMID: 31415129

33. Choukroun J, Ghanaati S. Reduction of relative centrifugation force within injectable platelet-rich-fibrin (PRF) concentrates advances patients' own inflammatory cells, platelets and growth factors: the first introduction to the low speed centrifugation concept. Eur J Trauma Emerg Surg. 2018:44(1):8795. https://doi.org/10.1007/s00068-017-0767-9.

34. Zhang J, Yin C, Zhao Q, Zhao Z, Wang J, Miron RJ, et al. Anti-inflammation effects of injectable platelet-rich fibrin via macrophages and dendritic cells. J Biomed Mater Res A. 2020;108(1):61-8. https://doi.org/10.1002/jbm.a.3 6792.

35. Jasmine S, Thangavelu A, Janarthanan K, Krishnamoorthy R, Alshatwi AA. Antimicrobial and antibiofilm potential of injectable platelet rich fibrin-a second-generation platelet concentrate-against biofilm producing oral staphylococcus isolates. Saudi J Biol Sci. 2020;27(1):41-6. https://doi.org/10.1 016/j.jjbs.2019.04.012.

36. Rafiee A, Memarpour M, Najibi Y, et al. Antimicrobial efficacy of a novel antibiotic-eluting injectable platelet-rich fibrin scaffold against a dualspecies biofilm in an infected immature root canal model. Biomed Res Int. 2020;2020:6623830.

37. Wang X, Zhang Y, Choukroun J, Ghanaati S, Miron RJ. Effects of an injectable platelet-rich fibrin on osteoblast behavior and bone tissue formation in comparison to platelet-rich plasma. Platelets. 2018;29(1):48-55. https://doi.org/10.1080/09537104.2017.1293807.

38. Kyyak S, Blatt S, Pabst A, Thiem D, Al-Nawas B, Kammerer PW. Combination of an allogenic and a xenogenic bone substitute material with injectable platelet-rich fibrin - a comparative in vitro study. J Biomater Appl. 2020; 35(1):83-96. https://doi.org/10.1177/0885328220914407.

39. Amaral Valladao CA Jr, Freitas Monteiro M, Joly JC. Guided bone regeneration in staged vertical and horizontal bone augmentation using platelet-rich fibrin associated with bone grafts: a retrospective clinical study. Int J Implant Dent. 2020;6(1):72. https://doi.org/10.1186/s40729-020-00266-y.

40. Ucak Turer O, Ozcan M, Alkaya B, Surmeli S, Seydaoglu G, Haytac MC. Clinical evaluation of injectable platelet-rich fibrin with connective tissue graft for the treatment of deep gingival recession defects: a controlled randomized clinical trial. J Clin Periodontol. 2020;47(1):72-80. https://doi. org/10.1111/jcpe.13193.

41. Kontakiotis E, Filippatos C, Tzanetakis G, Agrafioti A. Regenerative endodontic therapy: a data analysis of clinical protocols. J Endod. 2015; 41(2):146-54. https://doi.org/10.1016/j.joen.2014.08.003.

42. Thanasrisuebwong P, Kiattavorncharoen S, Surarit R, Phruksaniyom C, Ruangsawasdi N. Red and yellow injectable platelet-rich fibrin demonstrated differential effects on periodontal ligament stem cell proliferation, migration, and osteogenic differentiation. Int J Mol Sci. 2020;21(14):5153. https://doi.org/10.3390/ijms21145153.

43. AAE clinical considerations for a regenerative procedure [https://www.aae. org/specialty/wp-content/uploads/sites/2/2017/06/currentregenera tiveendodonticconsiderations.pdf].

44. Galler KM, Krastl G, Simon S, Van Gorp G, Meschi N, Vahedi B, et al. European Society of Endodontology position statement: revitalization procedures. Int Endod J. 2016;49(8):717-23. https://doi.org/10.1111/iej.12629.

45. Ruparel NB, Teixeira FB, Ferraz CC, Diogenes A. Direct effect of intracanal medicaments on survival of stem cells of the apical papilla. J Endod. 2012; 38(10):1372-5.

46. He L, Kim SG, Gong Q, Zhong J, Wang S, Zhou X, et al. Regenerative endodontics for adult patients. J Endod. 2017;43(95):S57-64. https://doi. org/10.1016/j.joen.2017.06.012.
47. Marx RE. Platelet-rich plasma: evidence to support its use. J Oral Maxillofac Surg. 2004;62(4):489-96. https://doi.org/10.1016/j.joms.2003.12.003.

48. Li X, Hou J, Wu B, Chen T, Luo A. Effects of platelet-rich plasma and cell coculture on angiogenesis in human dental pulp stem cells and endothelial progenitor cells. J Endod. 2014;40(11):1810-4. https://doi.org/10.1016/j.joen.2 014.07.022.

49. Khademi AA, Dianat O, Mahjour F, Razavi SM, Younessian F. Outcomes of revascularization treatment in immature dog's teeth. Dent Traumatol. 2014; 30(5):374-9. https://doi.org/10.1111/edt.12100.

50. Kobayashi E, Fluckiger L, Fujioka-Kobayashi M, Sawada K, Sculean A, Schaller $B$, et al. Comparative release of growth factors from PRP, PRF, and advanced-PRF. Clin Oral Investig. 2016;20(9):2353-60. https://doi.org/10.1 007/s00784-016-1719-1.

51. Torabinejad M, Milan M, Shabahang S, Wright KR, Faras H. Histologic examination of teeth with necrotic pulps and periapical lesions treated with 2 scaffolds: an animal investigation. J Endod. 2015;41(6):846-52. https://doi. org/10.1016/j.joen.2015.01.026.

52. Miron RJ, Chai J, Zheng S, Feng M, Sculean A, Zhang Y. A novel method for evaluating and quantifying cell types in platelet rich fibrin and an introduction to horizontal centrifugation. J Biomed Mater Res A. 2019; 107(10):2257-71. https://doi.org/10.1002/jbm.a.36734.

53. Dohle E, El Bagdadi K, Sader R, Choukroun J, James Kirkpatrick C, Ghanaati S. Platelet-rich fibrin-based matrices to improve angiogenesis in an in vitro coculture model for bone tissue engineering. J Tissue Eng Regen Med. 2018; 12(3):598-610. https://doi.org/10.1002/term.2475.

54. Bakhtiar H, Esmaeili S, Fakhr Tabatabayi S, Ellini MR, Nekoofar MH, Dummer PM. Second-generation platelet concentrate (platelet-rich fibrin) as a scaffold in regenerative endodontics: a case series. J Endod. 2017:43(3):4018. https://doi.org/10.1016/j.joen.2016.10.016.

55. Wend S, Kubesch A, Orlowska A, al-Maawi S, Zender N, Dias A, et al. Reduction of the relative centrifugal force influences cell number and growth factor release within injectable PRF-based matrices. J Mater Sci Mater Med. 2017;28(12):188. https://doi.org/10.1007/s10856-017-5992-6.

56. Kubesch A, Barbeck M, Al-Maawi S, et al. A low-speed centrifugation concept leads to cell accumulation and vascularization of solid platelet-rich fibrin: an experimental study in vivo. Platelets. 2019;30(3):329-40. https://doi. org/10.1080/09537104.2018.1445835.

57. Miron RJ, Chai J, Zhang P, Li Y, Wang Y, Mourão CFAB, et al. A novel method for harvesting concentrated platelet-rich fibrin (C-PRF) with a 10fold increase in platelet and leukocyte yields. Clin Oral Investig. 2020;24(8): 2819-28. https://doi.org/10.1007/s00784-019-03147-w.

58. Andreasen J, Paulsen H, Yu Z, Bayer T. A long-term study of 370 autotransplanted premolars. Part IV. Root development subsequent to transplantation. Eur J Orthod. 1990;12(1):38-50. https://doi.org/10.1093/ ejo/12.1.38.

59. Laureys WG, Cuvelier CA, Dermaut LR, De Pauw GA. The critical apical diameter to obtain regeneration of the pulp tissue after tooth transplantation, replantation, or regenerative endodontic treatment. J Endod. 2013;39(6):759-63. https://doi.org/10.1016/j.joen.2013.02.004.

60. Silujiai J, Linsuwanont P. Treatment outcomes of apexification or revascularization in nonvital immature permanent teeth: a retrospective study. J Endod. 2017;43(2):238-45.

61. Trevino EG, Patwardhan AN, Henry MA, Perry G, Dybdal-Hargreaves N, Hargreaves KM, et al. Effect of irrigants on the survival of human stem cells of the apical papilla in a platelet-rich plasma scaffold in human root tips. J Endod. 2011;37(8):1109-15. https://doi.org/10.1016/j.joen.2011.05.013.

62. Petrino J, Boda K, Shambarger S, Bowles W, McClanahan S. Challenges in regenerative endodontics: a case series. J Endod. 2010;36(3):536-41.

63. Berkhoff JA, Chen PB, Teixeira FB, Diogenes A. Evaluation of triple antibiotic paste removal by different irrigation procedures. J Endod. 2014;40(8):1172-7. https://doi.org/10.1016/j.joen.2013.12.027.

64. Liu S, Wang S, Dong Y. Evaluation of a bioceramic as a pulp capping agent in vitro and in vivo. J Endod. 2015;41(5):652-7. https://doi.org/10.1016/j. joen.2014.12.009.

\section{Publisher's Note}

Springer Nature remains neutral with regard to jurisdictional claims in published maps and institutional affiliations. 